\title{
Advances in studies on imaging and artificial intelligence technology-assisted difficult airway assessment
}

\author{
Jie Wang, Ming Xia, Hong Jiang \\ Department of Anesthesiology, The Ninth People's Hospital, Shanghai Jiaotong University School of Medicine, Shanghai, China \\ Contributions: (I) Conception and design: J Wang, M Xia; (II) Administrative support: None; (III) Provision of study materials or patients: None; (IV) \\ Collection and assembly of data: J Wang, M Xia; (V) Data analysis and interpretation: J Wang, H Jiang; (VI) Manuscript writing: All authors; (VII) \\ Final approval of manuscript: All authors. \\ Correspondence to: Hong Jiang. Department of Anesthesiology, The Ninth People's Hospital, Shanghai Jiaotong University School of Medicine, \\ Manufacturing Bureau Road 639, Huangpu District, Shanghai, China. Email: jianghongjiuyuan@163.com.
}

\begin{abstract}
Endotracheal intubation is an indispensable part to ensure oxygen supply for patients who undergo general anesthesia in surgeries. However, despite great progress and improvement in intubation technology and equipment, the incidence of perioperative complications and disabilities caused by difficult airway has not been well improved, especially for unpredictable difficult airway. At present, the accuracy of the difficult airway assessment methods are not high and the process is complex, so it is our focus to optimize the difficult airway prediction process and improve the prediction accuracy. At present, imaging and artificial intelligence (AI) face recognition technology as an aid to the assessment of difficult airways is significantly better than the traditional assessment methods. However, imaging techniques such as X-ray, CT, MRI, and ultrasound have their own clinical application value, while at the same time have many limitations, such as radiation, medical costs, equipment requirements, and medical staff burden, which prevent them from being widely used in clinical practice. On the other hand, AI technology in difficult airway identification is still in the sprouting stage, with the technology being immature and lacks sufficient research evidence to support it. For this reason, we have reviewed the literature on imaging technology and AI technology-assisted assessment of difficult airway in recent years, and we hope to provide new ideas for further research and to shed light on the emergence of a convenient and accurate method for difficult airway early warning, thus optimizing the clinical workflow, reducing the risk of misclassification, and ensuring the perioperative life safety of patients.
\end{abstract}

Keywords: Difficult airway; image-assisted; artificial intelligence (AI); difficult intubation; difficult laryngoscopy

Received: 07 November 2020; Accepted: 23 February 2021; Published: 30 March 2021.

doi: $10.21037 /$ fomm-20-79

View this article at: http://dx.doi.org/10.21037/fomm-20-79

\section{Introduction}

Endotracheal intubation is a key measure to ensure airway patency and oxygenation in patients undergoing surgery, and it has become an important guarantee for the safety of patients' life throughout the perioperative period. Although there have been great innovations and improvements in intubation equipment and intubation skills, the incidence of deaths and injuries caused by difficult airway, especially unexpected ones, remains high. In the 1996-2004 analysis of medical-related claims registered by the Danish Patient Insurance Association, anesthesia-related claims accounted for $4.5 \%$, of which deaths caused by airway management accidents accounted for about $17 \%$ of deaths (1). In the meantime, an analysis of claims related to airway management in the United Kingdom (2) and the United States (3) indicates that intubation difficulties or ventilation disorders are important causes of serious injury, brain damage or death. The latest claim analysis found that the proportion of patients with difficult intubation who had 
ASA grades III to V increased significantly in 2000-2012 compared with the proportion in 1993-1999. More and more complex strategies for coping with difficult airways are required. The incidence of difficult airways during the nonperioperative period increased significantly, and the predictable difficult airway events during the perioperative period showed an upward trend. In 80 emergency airway events that could not be intubated and unable to be oxygenated, delayed tracheotomy resulted in deaths exceeding one-third (4). The Difficult Airway Management Guidelines particularly emphasizes the importance of difficult airway identification and announcement. Careful evaluation of difficult airways should be used to adopt reasonable solutions to reduce the trauma that otherwise might have not been caused by airway interventions and ensure patient oxygenation to improve the safety of their lives (5). At present, there are many methods for evaluating difficult airways, including many bedside screening tests, physiopathological factors, related medical history, and simple risk scores and so on, but their sensitivity is generally low, and the probabilities for clinicians to successfully identify difficult airways by using this information are also very different, so there is no gold standard for prediction so far (6-8). However, X-ray, CT, MRI, ultrasound and other imaging techniques are often the gold standard for disease diagnosis and screening. They can intuitively display anatomical features and can be parametrically processed into anatomical images to help doctors identify lesions and assist doctors in making a diagnosis, therefore, anesthesiologists believe that the use of image-assisted assessment such as imaging technology can help find differences in the internal structure of the airway in patients with difficult airways, through which potential dangers of the difficult airway can be identified beforehand. Therefore, this article summarizes the researches on the prediction of difficult airways by image-assisted assessment methods represented by imaging and artificial intelligence (AI) face recognition technology in recent years and provides new ideas for the study of clinically difficult airway recognition.

\section{Imaging technology}

\section{$X$-ray predicts difficult airway}

Skull lateral X-ray can observe the bony structural changes in the airway anatomy, the linear distance from the mandibular alveolar line to the hyoid bone (ALH) and the linear distance from the inner edge of the mandible to the hyoid bone (MPH) and the distance from the chin vertex to the attachment of the apex of the lower incisor and the hyoid bone (SMD) are imaging indices reflecting tongue enlargement, which may be related to difficult laryngoscopy. In 90 patients with acromegaly undergoing pituitary tumor surgery, Lee et al. found that the difficult laryngoscopy group had longer ALH and MPH than the easy laryngoscopy group (54.5 vs. $45.8 \mathrm{~mm}, \mathrm{P}<0.001$; 22.4 vs. 16.2, $\mathrm{P}=0.003)$, and the $\mathrm{SMD}$ was shorter (26.3 vs. $29.4 \mathrm{~mm}, \mathrm{P}=0.009$ ) (9). A recent meta-analysis found that the predictive value of $\mathrm{X}$-rays for difficult airways was significantly better than the Mallampati classification, with sensitivity and specificity of 0.78 and 0.88 , negative and positive predictive values of 0.27 and 5.03, and AUC of 0.8970 with Q * index 0.8280 (10). We could find that although the $\mathrm{X}$-ray makes up for the lack of subjective evaluation and provides a good tool for measuring bone markers, a combination of several studies showed that its sensitivity and positive predictive value are still not in the best state and that there is great heterogeneity, which may be due to the large sample demand, and the risks of delayed intervention and radiation exposure make the sample population different. The three-blind prospective study of Kamalipour et al. (11) also proved this finding. The study by Khan et al. (12) similarly showed that X-rays are not suitable for clinical difficult airway assessment. In conclusion, although $\mathrm{X}$-rays can observe abnormal airway bony structures in patients with difficult airways and have some application value, they still cannot be used clinically as a necessary tool for the evaluation of difficult airways, considering its adverse hazards such as radiation and the problems of sensitivity and specificity of diagnosis.

\section{Neck CT predicts difficult airway}

Airway CT three-dimensional reconstruction technology can better observe the three-dimensional structure of airway anatomy and its physiological and pathological changes. Kim et al. (13) studied the relationship between the length and volume of the upper airway and the severity of OSAS by using 3D multi-slice spiral CT upper airway reconstruction technology. The airway length is expressed as the vertical distance from the hard palate to the hyoid bone in the median sagittal plane, and the volume is expressed as the cross-sectional area from the hard palate to the hyoid bone. In the multiple stepwise regression analysis models, it is found that the airway length is an important variable in the prediction of apnea and hypopnea indices in patients with severe OSAS (AHI, $r=0.523, \mathrm{P}<0.000$ ), while 
airway volume is not relevant. Lee et al. (9) reported that CT measurement of the tongue area can predict difficult laryngoscopy. In the univariate regression model, the accuracy of the tongue area to predict difficult laryngoscopy was $65 \%$. In the multiple regression model, age (OR $=1.084, \mathrm{P}=0.002)$ and tongue area $(\mathrm{OR}=1.002, \mathrm{P}=0.014)$ are independent risk factors for difficult laryngoscopy, and the AUC value of age and tongue area predicting difficult airway is 0.80 . When the best-predicted cut-off point of the tongue area is $2,600 \mathrm{~mm}^{2}, \mathrm{PPV}$ is $37 \%$ and NPV is $89 \%$. Han et al. (14) reported a case of successful use of airway CT three-dimensional reconstruction technology to assist in making a 3D printed model of the patient's airway for evaluation of difficult airways. In cases, by repeatedly trying the intubation procedure on the $3 \mathrm{D}$ printed model, the doctor adopted a more comprehensive response for the airway management of the patient after total laryngectomy, avoiding repeated intubation and incomplete intubation prepare for unnecessary harm to patients. Grimes et al. (15) reviewed the history of maxillofacial CT and nasal intubation in 77 patients undergoing temporomandibular joint surgery and found that the predicted nasal intubation difficulty on CT was significantly related to the actual nasal intubation difficulty (nasal diameter $\leq 6.3 \mathrm{~mm}$ indicates nasal intubation difficulty). The negative predictive value and positive predictive value of CT predicting in nasal intubation difficulty were $90.7 \%$ and $71.4 \%$, respectively. To a certain extent, 3D CT can be used as an auxiliary evaluation tool for patients with very poor airway conditions. However, there are limitations to the use of CT for clinical difficult airway early warning, such as radiation risk, medical burden, equipment requirements, and human and material resources, as well as the long operation time and large space required for CT. Therefore, $\mathrm{CT}$ is neither simple nor convenient as a tool for difficult airway assessment. In conclusion, although CT itself is not a simple assessment method, it can help physicians to some extent to identify potential difficult airways in patients preoperatively, especially in patients with high-risk head, neck and maxillofacial surgery.

\section{Neck MRI predicts difficult airway}

Unlike X-ray and CT, MRI does not have ionizing radiation exposure but uses the positively charged hydrogen nuclei in different tissues in a strong magnetic field to absorb and re-emit electromagnetic waves of a specific frequency or "resonance" frequency to form an internal structure image, which can present $2 \mathrm{D}$ or $3 \mathrm{D}$ images of anatomical structures digitally and is especially suited for observing soft tissue structures (16). Therefore, MRI is a good tool to evaluate the influence of airway soft tissue structure on difficult laryngoscope. Münster et al. analyzed the MRI data of 142 patients with difficult laryngoscopy and found that the position of the vocal cords was closely related to the difficult laryngoscopy. Vocal cords of $37 \%$ of patients in the difficult group are close to the cranial pyramid, and those of $55 \%$ of patients in the easy group are located in the fifth cervical spine (17). However, MRI is expensive and time-consuming, and these are the biggest problems to be overcome in clinical research. Due to the need for a large sample size and MRI technology, currently, the study is just an enhanced research design, which has many limitations, but it still tells us when conducting difficult airway assessment, it is necessary to combine MRI scan results with clinical investigations. In conclusion, there is very little research evidence supporting the effectiveness of MRI as a means of difficult airway assessment, mainly because of the need to overcome the difficulties of sample size and medical costs and time-consuming clinical studies. Clearly, MRI avoids the radiation problems of methods such as CT and X-ray, and has the characteristics of observing structural changes in the soft tissues of the airway, it is thus an important adjunctive assessment tool.

\section{Ultrasound predicts difficult airway}

Like CT, MRI, and X-ray, ultrasound can not only present the airway structure in the form of parametric images, but it has more advantages. It is portable, inexpensive, with no radiation, and can observe changes in airway structure in real-time. It is a very potent tool for airway assessment (18-21). Researchers used ultrasound to measure some indicators of the head and neck to assess difficult airways. Among them, the most studied was the thickness of the anterior cervical soft tissue, mainly including the thickness of the anterior epiglottis, the thickness of the anterior hyoid bone, the thickness of the anterior vocal cord, the thickness of the lateral pharyngeal wall, and the distance from the base of the tongue to the skin. Other indicators include tongue thickness and volume, oral exposure ratio, hyomental distance (HMD), and its derivative ratio, and comprehensive evaluation model.

\section{Thickness of anterior neck soft tissue}

The thickness of the anterior cervical soft tissue was 
measured at the level of the hyoid bone, epiglottis, cricothyroid membrane, thyroid isthmus, suprasternal notch, and vocal cords. When measured, the patient should be asked to lie supine and put the head in a neutral position. Generally, a 6-13 MHz high-frequency ultrasonic transducer is used for ultrasonic scanning $(22,23)$. The linear ultrasonic probe is placed vertically on the larynx to measure the vertical distance between the skin and six different anatomical sites.

The study of Ezri et al. (24) showed that the thickness of fat tissue in the anterior cervical region of Israeli obese patients detected by ultrasound is a good independent predictor of difficulty of laryngoscopy, and the prediction performance is better than the body mass index (BMI). A neck circumference $>50 \mathrm{~cm}$ and a soft tissue thickness before the vocal cord $>28 \mathrm{~mm}$ indicate a difficult laryngoscope. However, Komatsu et al. (25) conducted a similar study on obese patients in the United States, and found that the thickness of the soft tissues in the anterior cervical spine is not a risk factor for predicting difficult laryngoscope, nor can it distinguish between patients with easy and difficult intubation. The difference between the results of these two studies may have been caused by different races and body types of study objects. In a pilot study on morbidly obese patients, it was confirmed that the diagnostic specificity and sensitivity of the thickness of the anterior cervical soft tissue predicting difficult airway were $75 \%$ (26).

Measuring the thickness of the anterior cervical soft tissue in non-obese patients at the hyoid bone and epiglottis level can predict the difficulty of laryngoscopy (27-30). Falcetta and colleagues (29) reported that the best predictors of limited or difficult laryngoscopy were the median distance from the skin to the epiglottis at the level of the thyroglossal membrane (preepiglottic gap) (AUC: 0.906; 95\% CI: 0.86-0.93) and epiglottic area (AUC: 0.93; CI: $0.89-0.95$ ); Their cut-off values are $2.54 \mathrm{~cm}$ (sensitivity $82 \%$; specificity $91 \%$ ) and $5.04 \mathrm{~cm}^{2}$ (sensitivity $85 \%$; specificity $88 \%$ ) respectively. It is worth noting that gender shows different diagnostic value in the index of the median distance from skin to the epiglottis. The AUC for female patients was 0.94 (CI: $0.90-0.97$ ), with the sensitivity of $100 \%$ and specificity of $83 \%$; the AUC for male patients was 0.86 (CI: $0.80-0.91$ ), with the sensitivity of $75 \%$ and specificity of $92 \%$. Pinto et al. (30) also found that the thickness of the anterior epiglottis soft tissue was closely related to difficult laryngoscope. The optimal threshold is $27.5 \mathrm{~mm}$, the diagnostic accuracy is $74.3 \%$, and the sensitivity and specificity are $64.7 \%$ and $77.1 \%$, respectively.
Wu et al. (27) showed that the thickness of the anterior hyoid bone soft tissue was significantly related to the difficulty of exposure with the laryngoscope. The best cutoff value is $1.28 \mathrm{~cm}$ (sensitivity $85.7 \%$, specificity $85.1 \%$ ). The study of Bilici et al. (31) showed that the thickness of the pharyngeal lateral wall is the most significant factor in predicting the severity of OSA. The study of Au et al. (32) also showed that the thickness of the lateral pharyngeal wall and the position of the hyoid bone measured by ultrasound are risk factors related to OSA. Lower bone position and a thicker pharyngeal wall will increase the risk of OSA. However, we can see from many studies that the accuracy of measuring the thickness of the anterior cervical soft tissue at different levels to predict difficult airways is different, and is also different in different studies at the same level $(21,27,29,30,33-35)$, but most studies believe that it is an independent risk factor (27) because it may hinder the activity of the pharynx and the laryngoscope. In conclusion, almost all evidence suggests that the thickness of the anterior cervical soft tissue is an important predictor of a difficult airway.

\section{Tongue measurements}

When measuring the tongue with ultrasound, the doctor needs to instruct the patient to take the supine position with their head thrown back. In order to maintain the state of the tongue consistent, the patient is required to keep the mouth closed, the tongue tip gently touches the incisors and the tongue relaxed, and makes no sound. The examiner can easily obtain the parameters of the thickness, volume, cross-sectional area of the tongue, and tongue-tooral cavity ratio by placing the ultrasound probe in the midsagittal plane under the chin. Yadav et al. (36) found that the sensitivity and specificity of tongue thickness to predict difficult airways were $69.6 \%$ and $77 \%$, respectively. In the study of Yao and colleagues (37), it was shown that the tongue thickness of more than $6.1 \mathrm{~cm}$ was an independent risk factor for predicting difficult intubation, with an AUC of 0.78 and sensitivity and specificity of 0.75 and 0.72 , respectively. Increasing the ratio of tongue thickness to thyromental distance can significantly improve the prediction accuracy, with an AUC of 0.86 and sensitivity and specificity of 0.84 and 0.79 , respectively. However, the research of Andruszkiewicz et al. (38) found that among the 9 ultrasonic airway examination parameters, tongue parameters, especially tongue volume, have the greatest diagnostic power for difficult airways, but their sensitivity and positive predictive value are only $31.8 \%$ and 1.01 . 
In the prospective double-blind study of Parameswari et al. (34), tongue parameters also showed little diagnostic value. The diagnostic sensitivity and specificity of tongue volume were 66.7 and 62.7 , respectively, with positive predictive value and negative predictive value of 15.4 and 94.6. The results of these clinical studies are not comparable, because the sample size of their main outcome is limited, and they cannot select patients randomly. In a word, these studies include only a single group and lack large-scale samples including obese patients, children and adolescents, but they all indicate that the volume and thickness of the tongue may be a potential factor affecting laryngoscopy.

\section{HMDs with derived ratios}

Placing the ultrasound probe in the mid-sagittal position of the submental can also distinctly display the clear and highly echogenic hyoid bone and mandible structure. The HMD is the distance from the edge of the hyoid bone to the chin tip when the probe is in the mid-sagittal position. The hyomental distance ratio (HMDR) refers to the ratio of the HMD measured in the extended position to the distance measured in the neutral position. A study by Kalezić et al. (39) found that if the patient's head and neck are in the hyperextension position, HMD $\leq 5.3 \mathrm{~cm}$ or in the neutral position, HMD $\leq 5.5 \mathrm{~cm}$ or HMDR $\leq 1.2$ is of great significance in predicting difficult intubation, and HMDR is the best predictor of difficult intubation with the sensitivity of $95.6 \%$, and the specificity of $69.2 \%$. The two studies by Petrişor et al. $(35,40)$ have verified that HMD and HMDR are important factors in predicting difficult airways, and HMDR is believed to be more accurate in predicting difficult airways than HMD. Their studies found that when the ratio of sniffing position to neutral position is $\leq 1.06$, the sensitivity and specificity are $57 \%$ and $93 \%$, and respectively, the AUC is 0.73 , and the ratio of the hyperextension position to the neutral position has higher sensitivity. The optimal threshold of HMDR is 1.24, with a relatively high sensitivity of $86 \%$, a specificity of $72 \%$, and AUC of 0.82. The study by Andruszkiewicz et al. (38) found that the predictive sensitivity and positive predictive value of HMDR were only $42.9 \%$ and $56.2 \%$, while the specificity and negative predictive value performed well. For the differences in the diagnostic value of this parameter, a large-sample multi-center study may need to be further explored. In conclusion, the value of HMDR and its derived ratios for predicting difficult airways is controversial, but the vast majority of studies suggest a greater significance of
HMDR2 over HMDR1 (26,35,39).

In brief, the difficult airway early warning methods summarized in Table 1 are divided into four categories: X-ray, CT, MRI, and the US to provide early warning of a difficult airway. The main parameters and main conclusions involved are shown in Table 1.

\section{Other parameter measurement}

Poor range of motion of the temporomandibular joint has been widely recognized as one of the significant risk factors affecting tracheal intubation. Yao et al. (40) used ultrasound to measure the translational displacement of the mandibular condyle during the opening process of mouth and quantify the range of motion of the temporomandibular joint. The study found that the condyle translation $\leq 10 \mathrm{~mm}$ indicates difficulty in laryngoscopy, and the AUC is 0.93 . Gupta et al. (42) found that the soft tissue distance of pre-epiglottis divided by the distance from the epiglottis to the midpoint of the vocal cord (PE/E-VC) may be an independent risk factor for predicting difficult laryngoscopy with a sensitivity of $67-68 \%$. However, some studies have shown that the sensitivity and specificity of this parameter vary greatly in different studies, and it is not recommended as an indicator of difficult airway screening $(33,43,44)$.

\section{Al technology}

It is reported that AI has been used in medical work such as disease diagnosis and screening (45-49) and is used to predict the occurrence of perioperative adverse events by establishing large databases and machine deep learning $(50,51)$. In the prevention and control of COVID-19, AI has shown even more great advantages and value in adjunctive diagnosis, image analysis, drug development, temperature detection, robotic disinfection, pandemic modeling, and health management (52-54).

Attempts to use robots for anesthesia management and airway management have long been reported years ago, including studies that used TCI to administer drugs and achieve unmanned operation of tracheal intubation and nerve block, and to predict perioperative adverse events and give solutions $(55,56)$. Certainly, AI techniques have also been applied to assess difficult airways.

\section{AI combined with imaging-assisted modeling in difficult airways assessment}

With breakthroughs in $\mathrm{AI}$ algorithms and computing 
Table 1 Characteristics of selected imaging studies

\begin{tabular}{|c|c|c|c|c|c|}
\hline $\begin{array}{l}\text { Diagnostic } \\
\text { method }\end{array}$ & Author/year & $\mathrm{N}$ & $\begin{array}{l}\text { Main measured } \\
\text { parameters }\end{array}$ & $\begin{array}{l}\text { Reference } \\
\text { standard }\end{array}$ & Main conclusion \\
\hline \multirow[t]{2}{*}{ X-ray } & Lee (9)/2019 & 90 & ALH; MPH; SMD & C-L III-IV & $\begin{array}{l}\text { Difficult laryngoscope group has longer ALH and MPH } \\
\text { and shorter SMD }\end{array}$ \\
\hline & Khan (12)/2013 & 4,500 & ULBT; MHD; TMD & C-L III-IV & $\begin{array}{l}\text { X-ray parameters are not suitable for difficult airway } \\
\text { assessment }\end{array}$ \\
\hline \multirow[t]{2}{*}{ CT } & Lee $(9) / 2019$ & 90 & TA & C-L III-IV & $\begin{array}{l}\text { The accuracy of tongue area to predict difficult } \\
\text { laryngoscopy was } 65 \% \text {, with the best predicted cut- } \\
\text { off point being } 2,600 \mathrm{~mm}^{2}\end{array}$ \\
\hline & Grimes (15)/2016 & 77 & Nasal diameter & $\begin{array}{l}\text { Nasal diameter } \\
<\text { tracheal tube } \\
\text { inner diameter }\end{array}$ & $\begin{array}{l}\text { CT is an effective way to predict the difficulty of nasal } \\
\text { endotracheal intubation. Nose diameter } \leq 6.3 \mathrm{~mm} \text { is } \\
\text { difficult to intubate the nose }\end{array}$ \\
\hline MRI & Münster (17)/2016 & 142 & $\begin{array}{l}\text { Position of the vocal } \\
\text { cords }\end{array}$ & C-L III-IV & $\begin{array}{l}\text { Vocal cord close to the cranial position indicates a } \\
\text { high possibility of difficult airway }\end{array}$ \\
\hline \multirow[t]{6}{*}{ US } & Ezri (24)/2003 & 50 & $\begin{array}{l}\text { Neck circumference and } \\
\text { soft tissue thickness } \\
\text { before the vocal cord }\end{array}$ & C-L III-IV & $\begin{array}{l}\text { Neck circumference }>50 \mathrm{~cm} \text { and soft tissue thickness } \\
\text { before the vocal cord }>28 \mathrm{~mm} \text { indicate difficult } \\
\text { laryngoscope }\end{array}$ \\
\hline & Komatsu (25)/2007 & 64 & $\begin{array}{l}\text { Neck circumference and } \\
\text { soft tissue thickness } \\
\text { before the vocal cord }\end{array}$ & C-L III-IV & $\begin{array}{l}\text { Soft tissue thickness before the vocal cord is not } \\
\text { a good predictor of difficult laryngoscopy in obese } \\
\text { patients }\end{array}$ \\
\hline & Yadav $(36) / 2019$ & 310 & $\begin{array}{l}\text { Tongue thickness; soft } \\
\text { tissue thickness of the } \\
\text { anterior neck }\end{array}$ & C-L III-IV & $\begin{array}{l}\text { Measuring the thickness of the tongue and the } \\
\text { thickness of soft tissues in the front of the neck is } \\
\text { better than the bedside test }\end{array}$ \\
\hline & $\begin{array}{l}\text { Parameswari } \\
(34) / 2017\end{array}$ & 130 & TA & C-L III-IV & TA is an important predictor in difficult intubation \\
\hline & Kalezić (39)/2016 & 262 & HMDe; HMDn; HMDR & C-L III-IV & HMDR $\leq 1.2$ is the best predictor of difficult intubation \\
\hline & Petrisor (35)/2018 & 120 & $\mathrm{HMDR}_{1} ; \mathrm{HMD}_{\mathrm{R}} 2$ & C-L III-IV & $\begin{array}{l}\mathrm{HMDR}_{2} \text { is more sensitive than } \mathrm{HMDR}_{1} \text { in predicting } \\
\text { difficult airways with the optimal threshold } 1.24\end{array}$ \\
\hline
\end{tabular}

$\mathrm{N}$, sample size; SMD, the distance from the chin vertex to the attachment of the apex of the lower incisor and the hyoid bone; ALH, the linear distance from the mandibular alveolar line to the hyoid bone; MPH, the linear distance from the inner edge of the mandible to the hyoid bone; TMD, thyromental distance; MHD, mandibulohyoid distance; ULBT, upper lip bite test; mDSE, the median distance from skin to epiglottis; DTE, the distance between the thyroid cartilage and epiglottis; DST, the distance between the skin and thyroid cartilage; C-L, Cormack-Lehane classification; TA, tongue area; VT/VO, tongue volume/oropharyngeal cavity volume; HMDe, hyomental distance in extension; HMDn, hyomental distance in the neutral position; HMDR/HMDR ${ }_{2}$, HMDe/HMDn; $\mathrm{HMDR}_{1}$, ratio of sniffing position $\mathrm{HMD}_{\mathrm{HM}}$ neutral position HMD; AUC, area under the curve; DSHB, anterior neck soft tissue thickness at hyoid bone level; DSEM, anterior neck soft tissue thickness at thyrohyoid membrane level; DSAC, anterior neck soft tissue thickness at anterior commissure level. 
power, AI technology will surely calculate the characteristics that distinguish difficult airway patients from non-difficult airway patients. Langeron et al. (57) found that the predictive value of the computer-aided model constructed using the random forest algorithm was significantly better than the currently latest clinical predictive scale model and the predictive model constructed by traditional Logistic regression analysis, preliminarily proving that $\mathrm{AI}$ machine learning can provide better difficult airway prediction. Connor et al. (58) calculated the facial models of patients that are extremely easy or difficult for tracheal intubation. By analyzing and processing facial images through machine learning algorithms, they extracted key points of the face and tested the discriminative ability of each parameter through logistic regression. They also tested the discriminative ability of the combination of Mallampati classification and Thyromental Distance in detail. Through the maximum derivation and verification of AUC and crossvalidation of candidate models, the best face prediction model is finally selected. However, these two studies require imaging-assisted modeling, and there are some problems related to radiation and cost. Moreover, face recognition and feature acquisition technologies are not fully automatic but semi-automatic, because it requires manual measurement by placing fiducial markers for quantitative analysis. Besides, the study of Connor et al. excludes factors of race and does not conduct modeling analysis on the population whose tracheal intubation is neither easy nor difficult, so it is not universal.

\section{AI combined with facial images in difficult airways assessment}

Current methods of clinical assessment of the difficult airway tend to focus on intra-airway anatomy, appearance evaluation metrics and independent risk factors as well as improving predictive accuracy with the help of imaging techniques, and the assessment process is quite cumbersome. Recently, Cuendet et al. (59) made a fullautomatic system to collect patient's facial photos based on the researches above. They guided patients to complete different actions and facial expressions on the user interface developed by MATLAB and duly captured the data. The study did not use imaging to assist in modeling, Instead, it collected facial photos of patients with mouth open, tongue stretched out, head stretched vertically and laterally rotated. Then machine learning algorithms were used to analyze and process the facial photos. Combined with the actual results of tracheal intubation, the key facial features were extracted. Afterward, the correlation between facial features and difficult intubation was calculated by AI, and the classifier learned to select patients into groups of easy, mild and moderately severe intubation. The research model was experienced in 2,725 subjects and validated in 970 subjects, with an AUC value of 0.81 . The AUC value in the real world study was 0.779 . The study indicates that automatic face scanning can basically replace manual evaluation, but due to its small sample size, and the limitations of AI algorithm and computing force at that time, this study has some limitations, thus further in-depth research is still needed.

Comprehensive researches show that AI facial recognition technology is expected to replace experienced doctors in the fully automatic intelligent assessment of difficult airways and optimize clinical work to reduce the risk of misdiagnosis of difficult airways, which makes AI predicting difficult airways a field worthy of further researches. Besides, we believe that in addition to the patient's general medical history, physical examination factors, and facial features, the patient's existing head and neck imaging will contribute to the improvement of the intelligent assessment of difficult airways. How to extensively contact and use these data is also worth further consideration and researches.

\section{Conclusions}

The previous non-visualized difficult airway assessment method is too cumbersome and subjective, and their prediction accuracy is not high. However, imaging evaluation methods such as X-ray, CT, MRI, and ultrasound also have many limitations, such as radiation, medical expenses, equipment requirements, and medical personnel's burden, so they cannot be widely popularized. Nowadays, AI face recognition technology is expected to replace experienced doctors in the fully automatic and intelligent assessment of difficult airways, to optimize clinical workflows, and to reduce the risk of misjudgment. This information suggests that it is worth constant effort in the field of AI predicting difficult airways. We boldly speculate that with the breakthrough of AI algorithms and computing power and the development of advanced $3 \mathrm{D}$ facial recognition technology, facial recognition technology for early difficult airways warning will have more profound significance, Moreover, the patient's existing head and neck imaging images will also be an important part of realizing 
early difficult airway warning with AI. How to extensively contact and use these data is worthy of our discussion and research.

\section{Acknowledgments}

Funding: Clinical Research Plan of SHDC (No. SHDC2020CR3043B); Scientific Research Project of Shanghai Science and Technology Commission (18441904600).

\section{Footnote}

Conflicts of Interest: All authors have completed the ICMJE uniform disclosure form (available at https://fomm. amegroups.com/article/view/10.21037/fomm-20-79/coif). The authors have no conflicts of interest to declare.

Ethical Statement: The authors are accountable for all aspects of the work in ensuring that questions related to the accuracy or integrity of any part of the work are appropriately investigated and resolved.

Open Access Statement: This is an Open Access article distributed in accordance with the Creative Commons Attribution-NonCommercial-NoDerivs 4.0 International License (CC BY-NC-ND 4.0), which permits the noncommercial replication and distribution of the article with the strict proviso that no changes or edits are made and the original work is properly cited (including links to both the formal publication through the relevant DOI and the license). See: https://creativecommons.org/licenses/by-nc-nd/4.0/.

\section{References}

1. Hove LD, Steinmetz J, Christoffersen JK, et al. Analysis of deaths related to anesthesia in the period 1996-2004 from closed claims registered by the Danish Patient Insurance Association. Anesthesiology 2007;106:675-80.

2. Cook TM, MacDougall-Davis SR. Complications and failure of airway management. Br J Anaesth 2012;109:i68-85.

3. Metzner J, Posner KL, Lam MS, et al. Closed claims' analysis. Best Pract Res Clin Anaesthesiol 2011;25:263-76.

4. Joffe AM, Aziz MF, Posner KL, et al. Management of difficult tracheal intubation: a closed claims analysis. Anesthesiology 2019;131:818-29.

5. Frerk C, Mitchell VS, McNarry AF, et al. Difficult
Airway Society 2015 guidelines for management of unanticipated difficult intubation in adults. $\mathrm{Br} \mathrm{J}$ Anaesth 2015;115:827-48.

6. Roth D, Pace NL, Lee A, et al. Airway physical examination tests for detection of difficult airway management in apparently normal adult patients. Cochrane Database Syst Rev 2018;5:CD008874.

7. Detsky ME, Jivraj N, Adhikari NK, et al. Will this patient be difficult to intubate?: the rational clinical examination systematic review. JAMA 2019;321:493-503.

8. Teoh WH, Kristensen MS. Prediction in airway management: what is worthwhile, what is a waste of time and what about the future? Br J Anaesth 2016;117:1-3.

9. Lee HC, Kim MK, Kim YH, et al. Radiographic predictors of difficult laryngoscopy in acromegaly patients. J Neurosurg Anesthesiol 2019;31:50-6.

10. Ji C, Ni Q, Chen W. Diagnostic accuracy of radiology (CT, $\mathrm{X}$-ray, US) for predicting difficult intubation in adults: a meta-analysis. J Clin Anesth 2018;45:79-87.

11. Kamalipour H, Bagheri M, Kamali K, et al. Lateral neck radiography for prediction of difficult orotracheal intubation. Eur J Anaesthesiol 2005;22:689-93.

12. Khan $\mathrm{ZH}$, Arbabi S. Diagnostic value of the upper lip bite test in predicting difficulty in intubation with head and neck landmarks obtained from lateral neck X-ray. Indian J Anaesth 2013;57:381-6.

13. Kim EJ, Choi JH, Kim YS, et al. Upper airway changes in severe obstructive sleep apnea: upper airway length and volumetric analyses using 3D MDCT. Acta Otolaryngol 2011;131:527-32.

14. Han B, Liu Y, Zhang X, et al. Three-dimensional printing as an aid to airway evaluation after tracheotomy in a patient with laryngeal carcinoma. BMC Anesthesiol 2016;16:6.

15. Grimes D, MacLeod I, Taylor T, et al. Computed tomography as an aid to planning intubation in the difficult airway. Br J Oral Maxillofac Surg 2016;54:80-2.

16. Yousaf T, Dervenoulas G, Politis M. Advances in MRI methodology. Int Rev Neurobiol 2018;141:31-76.

17. Münster T, Hoffmann M, Schlaffer S, et al. Anatomical location of the vocal cords in relation to cervical vertebrae: a new predictor of difficult laryngoscopy? Eur J Anaesthesiol 2016;33:257-62.

18. Prasad A, Yu E, Wong DT, et al. Comparison of sonography and computed tomography as imaging tools for assessment of airway structures. J Ultrasound Med 2011;30:965-72.

19. Lien WC. Comments to role of upper airway ultrasound 
in airway management. J Intensive Care 2017;5:10.

20. Osman A, Sum KM. Role of upper airway ultrasound in airway management. J Intensive Care 2016;4:52.

21. Alessandri F, Antenucci G, Piervincenzi E, et al. Ultrasound as a new tool in the assessment of airway difficulties: an observational study. Eur J Anaesthesiol 2019;36:509-15.

22. Zheng BX, Zheng H, Lin XM. Ultrasound for predicting difficult airway in obstetric anesthesia: protocol and methods for a prospective observational clinical study. Medicine (Baltimore) 2019;98:e17846.

23. Petrisor C, Dîrzu D, Trancă S, et al. Preoperative difficult airway prediction using suprahyoid and infrahyoid ultrasonography derived measurements in anesthesiology. Med Ultrason 2019;21:83-8.

24. Ezri T, Gewürtz G, Sessler DI, et al. Prediction of difficult laryngoscopy in obese patients by ultrasound quantification of anterior neck soft tissue. Anaesthesia 2003;58:1111-4.

25. Komatsu R, Sengupta P, Wadhwa A, et al. Ultrasound quantification of anterior soft tissue thickness fails to predict difficult laryngoscopy in obese patients. Anaesth Intensive Care 2007;35:32-7.

26. Petrisor C, Szabo R, Constantinescu C, et al. Ultrasoundbased assessment of hyomental distances in neutral, ramped, and maximum hyperextended positions, and derived ratios, for the prediction of difficult airway in the obese population: a pilot diagnostic accuracy study. Anaesthesiol Intensive Ther 2018;50:110-6.

27. Wu J, Dong J, Ding Y, et al. Role of anterior neck soft tissue quantifications by ultrasound in predicting difficult laryngoscopy. Med Sci Monit 2014;20:2343-50.

28. Adhikari S, Zeger W, Schmier C, et al. Pilot study to determine the utility of point-of-care ultrasound in the assessment of difficult laryngoscopy. Acad Emerg Med 2011;18:754-8.

29. Falcetta S, Cavallo S, Gabbanelli V, et al. Evaluation of two neck ultrasound measurements as predictors of difficult direct laryngoscopy: a prospective observational study. Eur J Anaesthesiol 2018;35:605-12.

30. Pinto J, Cordeiro L, Pereira C, et al. Predicting difficult laryngoscopy using ultrasound measurement of distance from skin to epiglottis. J Crit Care 2016;33:26-31.

31. Bilici S, Engin A, Ozgur Y, et al. Submental ultrasonographic parameters among patients with obstructive sleep apnea. Otolaryngol Head Neck Surg 2017;156:559-66.

32. Au CT, Chan KCC, Liu KH, et al. Potential anatomic markers of obstructive sleep apnea in prepubertal children.
J Clin Sleep Med 2018;14:1979-86.

33. Reddy PB, Punetha P, Chalam KS. Ultrasonography - a viable tool for airway assessment. Indian J Anaesth 2016;60:807-13.

34. Parameswari A, Govind M, Vakamudi M. Correlation between preoperative ultrasonographic airway assessment and laryngoscopic view in adult patients: a prospective study. J Anaesthesiol Clin Pharmacol 2017;33:353-8.

35. Petrişor C, Szabo R, Constantinescu C, et al. The performance of ultrasound-based quantification of the hyomental distance ratio in predicting difficult airway in anaesthesia: a STARD-compliant prospective diagnostic study. Eur J Anaesthesiol 2018;35:627-8.

36. Yadav NK, Rudingwa P, Mishra SK, et al. Ultrasound measurement of anterior neck soft tissue and tongue thickness to predict difficult laryngoscopy - an observational analytical study. Indian J Anaesth 2019;63:629-34.

37. Yao W, Wang B. Can tongue thickness measured by ultrasonography predict difficult tracheal intubation? Br J Anaesth 2017;118:601-9.

38. Andruszkiewicz P, Wojtczak J, Sobczyk D, et al. Effectiveness and validity of sonographic upper airway evaluation to predict difficult laryngoscopy. J Ultrasound Med 2016;35:2243-52.

39. Kalezić N, Lakićević M, Miličić B, et al. Hyomental distance in the different head positions and hyomental distance ratio in predicting difficult intubation. Bosn J Basic Med Sci 2016;16:232-6.

40. Yao W, Zhou Y, Wang B, et al. Can mandibular condylar mobility sonography measurements predict difficult laryngoscopy? Anesth Analg 2017;124:800-6.

41. Liu J, Jiang H, Zhu Y. Value of 3D-CT reconstruction technology in predicting diffificult in patients with oropharyngeal tumor. Shanghai Med J 2009;32:29-33.

42. Gupta D, Srirajakalidindi A, Ittiara B, et al. Ultrasonographic modification of Cormack Lehane classification for pre-anesthetic airway assessment. Middle East J Anaesthesiol 2012;21:835-42.

43. Soltani Mohammadi S, Saliminia A, Nejatifard N, et al. Usefulness of ultrasound view of larynx in pre-anesthetic airway assessment: a comparison with Cormack-Lehane classification during direct laryngoscopy. Anesth Pain Med 2016;6:e39566.

44. Rana S, Verma V, Bhandari S, et al. Point-of-care ultrasound in the airway assessment: a correlation of ultrasonography-guided parameters to the CormackLehane classification. Saudi J Anaesth 2018;12:292-6. 
45. Golden JA. Deep learning algorithms for detection of lymph node metastases from breast cancer: helping artificial intelligence be seen. JAMA 2017;318:2184-6.

46. Cornish TC. Clinical application of image analysis in pathology. Adv Anat Pathol 2020;27:227-35.

47. Acs B, Rantalainen M, Hartman J. Artificial intelligence as the next step towards precision pathology. J Intern Med 2020;288:62-81.

48. Ibrahim A, Gamble P, Jaroensri R, et al. Artificial intelligence in digital breast pathology: techniques and applications. Breast 2020;49:267-273.

49. Wang J, Kato F, Yamashita H, et al. Automatic estimation of volumetric breast density using artificial neural networkbased calibration of full-field digital mammography: feasibility on Japanese women with and without breast cancer. J Digit Imaging 2017;30:215-27.

50. Thottakkara P, Ozrazgat-Baslanti T, Hupf BB, et al. Application of machine learning techniques to highdimensional clinical data to forecast postoperative complications. PLoS One 2016;11:e0155705.

51. Lee CK, Samad M, Hofer I, et al. Development and validation of an interpretable neural network for prediction of postoperative in-hospital mortality. NPJ Digit Med 2021;4:8.

52. Scimeca $M$, Urbano $N$, Bonfiglio R, et al. Imaging diagnostics and pathology in SARS-CoV-2-related

doi: $10.21037 /$ fomm-20-79

Cite this article as: Wang $\mathrm{J}$, Xia M, Jiang H. Advances in studies on imaging and artificial intelligence technologyassisted difficult airway assessment. Front Oral Maxillofac Med 2021;3:8. diseases. Int J Mol Sci 2020;21:6960.

53. Suri JS, Puvvula A, Biswas M, et al. COVID-19 pathways for brain and heart injury in comorbidity patients: A role of medical imaging and artificial intelligence-based COVID severity classification: a review. Comput Biol Med 2020;124:103960.

54. Boukhris M, Hillani A, Moroni F, et al. Cardiovascular implications of the COVID-19 pandemic: a global perspective. Can J Cardiol 2020;36:1068-80.

55. Hashimoto DA, Witkowski E, Gao L, et al. Artificial intelligence in anesthesiology: current techniques, clinical applications, and limitations. Anesthesiology 2020;132:379-94.

56. Connor CW. Artificial intelligence and machine learning in anesthesiology. Anesthesiology 2019;131:1346-59.

57. Langeron $\mathrm{O}$, Cuvillon $\mathrm{P}$, Ibanez-Esteve C, et al. Prediction of difficult tracheal intubation: time for a paradigm change. Anesthesiology 2012;117:1223-33.

58. Connor CW, Segal S. Accurate classification of difficult intubation by computerized facial analysis. Anesth Analg 2011;112:84-93.

59. Cuendet GL, Schoettker P, Yüce A, et al. Facial image analysis for fully automatic prediction of difficult endotracheal intubation. IEEE Trans Biomed Eng 2016;63:328-39. 